\title{
Solubility of Anthracene in Binary Alcohol + 2-Methoxyethyl Ether Solvent Mixtures
}

\author{
J oyce R. Powell, Karen S. Coym, and William E. Acree, J r.* \\ Department of Chemistry, University of North Texas, Denton, Texas 76203-0068
}

\begin{abstract}
Experimental solubilities are reported for anthracene dissolved in seven binary mixtures containing 2-methoxyethyl ether with 1-propanol, 2-propanol, 1-butanol, 2-butanol, 2-methyl-1-pentanol, 4-methyl2-pentanol, and 1-octanol at $25^{\circ} \mathrm{C}$. Results of these measurements are used to test two mathematical representations based upon the combined nearly ideal binary solvent (NIBS)/Redlich-Kister equation and modified Wilson model. For the seven systems studied, both equations were found to provide an accurate mathematical representation of the experimental data, with an overall average absolute deviation between measured and calculated values being $1.1 \%$ and $0.8 \%$ for the combined NIBS/Redlich-Kister and modified Wilson equations, respectively.
\end{abstract}

\section{Introduction}

Solid-liquid equilibrium data of organic nonelectrolyte systems are becoming increasingly important in the petroleum industry, particularly in light of present trends toward heavier feedstocks and known carcinogenicity/ mutagenicity of many of the larger polycyclic aromatic compounds. Solubility data for a number of polycyclic aromatic hydrocarbons (i.e, anthracene and pyrene) and heteroatom polynuclear aromatics (i.e., carbazole, dibenzothiophene, and xanthene) have been published in the recent chemical literature (for listing of references see Acree (1994, 1995a,b)). Despite efforts by experimentalists and scientific organizations, both in terms of new experimental measurements and critically-evaluated data compilations, there still exist numerous systems for which solubility data are not readily available.

To address this problem, researchers have turned to predictive methods as a means to generate desired quantities. Numerous equations have been suggested for predicting solute solubilities in binary solvent mixtures. For the most part, the predictive methods do provide fairly reasonable estimates for noncomplexing systems. There still remains, however, the need to develop better predictive expressions and mixing models to describe the more nonideal complexing systems believed to contain hydrogenbonding solvent components. Continued development of solution models for describing the thermodynamic properties of a solute in binary solvent systems requires that a large data base be available for assessing the applications and limitations of derived expressions. Currently, only a limited data base exists for crystalline nonelectrolyte solubility in binary solvent mixtures capable of undergoing hydrogen-bond formation. For this reason, anthracene solubilities were determined in seven binary alcohol + 2-methoxyethyl ether solvent mixtures. Results of these measurements are used to further test the descriptive abilities of several previously derived expressions.

\section{Experimental Methods}

Anthracene (Acros, 99.9+\%) was recrystallized several times from 2-propanone. 2-Methoxyethyl ether (Aldrich 99.5\%, anhydrous), 1-propanol (Aldrich 99+\%, anhydrous), 2-propanol (Aldrich 99+\%, anhydrous), 1-butanol (Aldrich

* To whom correspondence should be addressed. E-mail: acree@ casl.unt.edu.
HPLC, 99.8+\%), 2-butanol (Aldrich 99+\%, anhydrous), 2-methyl-1-pentanol (Aldrich 99\%), 4-methyl-2-pentanol (Acros 99+\%), and 1-octanol (Aldrich 99+\%, anhydrous) were stored over both anhydrous sodium sulfate and molecular sieves before use. Gas chromatographic analysis showed solvent purities to be 99.7 mol \% or better. Karl Fischer titration gave water contents (mass/mass \%) of $<0.01 \%$ for all seven alcohols used. Binary solvent mixtures were prepared by mass so that compositions could be calculated to 0.0001 mole fraction.

Excess solute and solvent were placed in amber glass bottles and allowed to equilibrate in a constant temperature water bath at $(25.0 \pm 0.1){ }^{\circ} \mathrm{C}$ for at last 3 days (often longer). Attainment of equilibrium was verified both by repetitive measurements after a minimum of three additional days and by approaching equilibrium from supersaturation by pre-equilibrating the solutions at a higher temperature. Aliquots of saturated anthracene solutions were transferred through a coarse filter into a tared volumetric flask to determine the amount of sample and diluted quantitatively with methanol for spectrophotometric analysis at $356 \mathrm{~nm}$ on a Bausch and Lomb Spectronic 2000. Concentrations of the dilute solutions were determined from a Beer-Lambert law absorbance versus concentration working curve derived from measured absorbances of standard solutions of known molar concentration. Molar absorptivities of the nine standard solutions varied systematically with molar concentration and ranged from approximately $\epsilon / \mathrm{L} \mathrm{mol}^{-1} \mathrm{~cm}^{-1}=7450$ to $\epsilon / \mathrm{L} \mathrm{mol}^{-1} \mathrm{~cm}^{-1}=$ 7150 for anthracene concentrations ranging from $\mathrm{C} / \mathrm{mol} \mathrm{L}^{-1}$ $=6.75 \times 10^{-5}$ to $\mathrm{C} / \mathrm{mol} \mathrm{L}^{-1}=2.25 \times 10^{-4}$. Experimental anthracene solubilities in the seven binary alcohol + 2-methoxyethyl ether mixtures studied are listed in Table 1. Numerical values represent the average of between four and eight independent determinations, with the measured values being reproducible to within $\pm 1.8 \%$.

\section{Results and Discussion}

Acree and co-workers (Acree and Zvaigzne, 1991; Acree et al., 1991; Acree 1992) suggested possible mathematical representations for isothermal solubility data based upon either a combined NIBS/Redlich-Kister model

$$
\ln x_{A}^{s a t}=x_{B}^{o} \ln \left(x_{A}^{s a t}\right)_{B}+x_{C}^{o} \ln \left(x_{A}^{s a t}\right)_{C}+x_{B}^{o} x_{C}^{o} \sum_{i=0}^{N} S_{i}\left(x_{B}^{o}-x_{C}^{o}\right)^{i}
$$


Table 1. Experimental Mole Fraction Solubilities of Anthracene $\left(x_{A}^{\text {sat }}\right)$ in Binary Alcohol (B) + 2-Methoxyethyl Ether (C) Solvent Mixtures at $25.0^{\circ} \mathrm{C}$

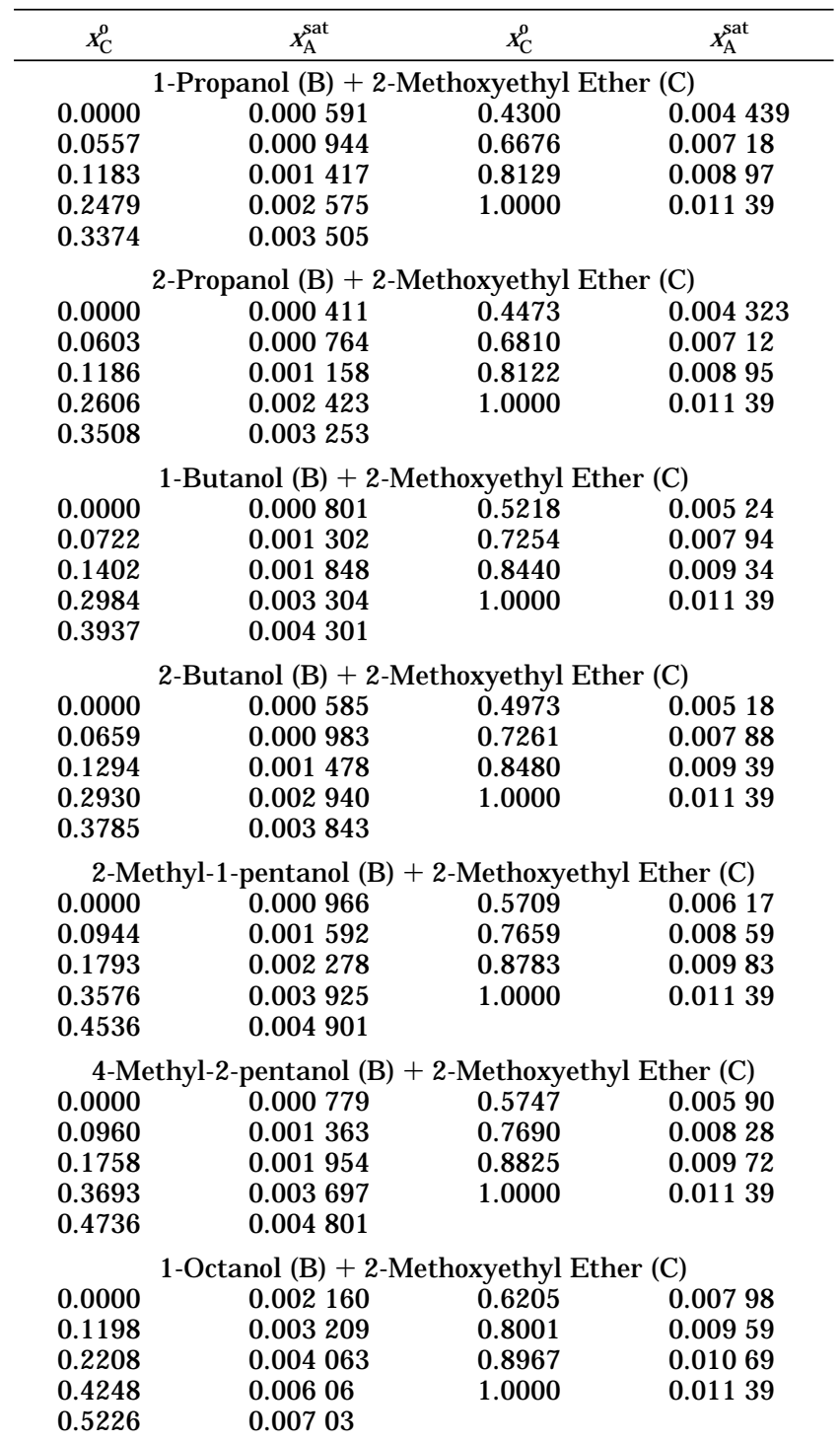

or modified Wilson equation (Comer and Kopecni, 1990)

$$
\begin{aligned}
& \ln \left[\mathrm{a}_{\mathrm{A}}(\mathrm{s}) / \mathrm{x}_{A}^{\mathrm{sat}}\right]=1-\mathrm{x}_{\mathrm{B}}^{\mathrm{o}}\left\{1-\ln \left[\mathrm{a}_{\mathrm{A}}(\mathrm{s}) /\left(\mathrm{x}_{A}^{\mathrm{sat}}\right)_{B}\right]\right\} /\left(\mathrm{x}_{\mathrm{B}}^{\mathrm{o}}+\right. \\
&\left.\mathrm{x}_{\mathrm{C}}^{\mathrm{o}} \Lambda_{\mathrm{BC}}^{\mathrm{adj}}\right)-\mathrm{x}_{\mathrm{C}}^{\mathrm{o}}\left\{1-\ln \left[\mathrm{a}_{\mathrm{A}}(\mathrm{s}) /\left(\mathrm{x}_{\mathrm{A}}^{\mathrm{sat}}\right)_{C}\right]\right\} /\left(\mathrm{x}_{\mathrm{B}}^{\mathrm{o}} \Lambda_{\mathrm{CB}}^{\mathrm{adj}}+\mathrm{x}_{\mathrm{C}}^{\mathrm{o}}\right)
\end{aligned}
$$

where the various $S_{i}$ and $\Lambda_{i j}^{\text {adj }}$ "curve-fit" parameters can be evaluated via least squares analysis. In eqs 1 and 2 $\mathrm{x}_{\mathrm{B}}^{0}$ and $\mathrm{x}_{\mathrm{C}}^{\circ}$ refer to the initial mole fraction composition of the binary solvent calculated as if the solute were not present, $a_{A}(s)$ is the activity of the solute, and $\left(x_{A}^{\text {sat }}\right)_{i}$ is the saturated mole fraction solubility of the solute in pure solvent $i$. The solute activity is defined as the ratio of the fugacity of the solid to the fugacity of the hypothetical supercooled liquid solute. The numerical value of $a_{A}(s)=$ 0.00984 used in the modified Wilson computations was calculated from

$$
\text { In } \mathrm{a}_{\mathrm{A}}(\mathrm{s})=-\Delta_{\text {fus }} \mathrm{H}_{\mathrm{A}}\left(\mathrm{T}_{\mathrm{mp}}-\mathrm{T}\right) /\left(\mathrm{RTT}_{\mathrm{mp}}\right)
$$

the molar enthalpy of fusion, $\Delta_{\text {fus }} \mathrm{H}_{\mathrm{A}} / \mathrm{mol} \mathrm{mo}^{-1}=29370$ (Zhang et al., 1996), at the normal melting point temperature of the solute, $\mathrm{T}_{\mathrm{mp}} / \mathrm{K}=488.9$. Equation 3 assumes that the enthalpy of fusion is independent of temperature. Lack of heat capacity data necessitated this approximation.
Table 2. Mathematical Representation of Anthracene

\begin{tabular}{|c|c|c|c|c|}
\hline \multirow{2}{*}{$\begin{array}{l}\text { binary solvent system } \\
\text { component } B+\text { component } C\end{array}$} & \multicolumn{2}{|c|}{ eq 1} & \multicolumn{2}{|c|}{ eq 2} \\
\hline & $\mathrm{S}^{\mathrm{a}}$ & $\% \operatorname{dev}^{b}$ & $\overline{\Lambda_{\mathrm{ij}}^{\mathrm{adj}}}$ & $\% \operatorname{dev}^{b}$ \\
\hline 1-propanol + 2-methoxyethyl ether & $\begin{array}{l}2.704 \\
1.905 \\
1.609\end{array}$ & 1.1 & $\begin{array}{l}2.072 \\
0.187\end{array}$ & 0.7 \\
\hline 2-propanol + 2-methoxyethyl ether & $\begin{array}{l}3.099 \\
2.363 \\
2.555\end{array}$ & 2.3 & $\begin{array}{l}2.072 \\
0.129\end{array}$ & 1.1 \\
\hline 1-butanol + 2-methoxyethyl ether & $\begin{array}{l}2.182 \\
1.531 \\
1.185\end{array}$ & 1.4 & $\begin{array}{l}1.811 \\
0.216\end{array}$ & 1.6 \\
\hline 2-butanol +2 -methoxyethyl ether & $\begin{array}{l}2.740 \\
1.826 \\
1.221\end{array}$ & 1.1 & $\begin{array}{l}2.014 \\
0.187\end{array}$ & 0.6 \\
\hline $\begin{array}{l}\text { 2-methyl-1-pentanol }+ \\
\text { 2-methoxyethyl ether }\end{array}$ & $\begin{array}{l}1.958 \\
1.012 \\
0.504\end{array}$ & 0.5 & $\begin{array}{l}1.637 \\
0.274\end{array}$ & 0.5 \\
\hline $\begin{array}{l}\text { 4-methyl-2-pentanol }+ \\
\text { 2-methoxyethyl ether }\end{array}$ & $\begin{array}{l}2.125 \\
1.182 \\
0.556\end{array}$ & 0.5 & $\begin{array}{l}1.753 \\
0.274\end{array}$ & 0.4 \\
\hline 1-octanol + 2-methoxyethyl ether & $\begin{array}{l}1.232 \\
0.466 \\
0.407\end{array}$ & 0.8 & $\begin{array}{l}2.217 \\
0.448\end{array}$ & 0.7 \\
\hline
\end{tabular}
Solubilities in Several Binary Alcohol (B) + 2-Methoxyethyl Ether (C) Solvent Mixtures

a Combined NIBS/Redlich-Kister curve-fit parameters are ordered as $S_{0}, S_{1}$, and $S_{2} .{ }^{b}$ Deviation $(\%)=(100 / 7) \sum \mid\left[\left(x_{A}^{\text {sat }}\right)^{\text {calc }}-\right.$ $\left.\left(x_{A}^{\text {sat }}\right)^{\exp }\right] /\left(x_{A}^{\text {sat }}\right)^{\exp } \mid{ }^{\text {c }}$ Adjustable parameters for the modified Wilson equation are ordered as $\Lambda_{\mathrm{BC}}^{\mathrm{adj}}$ and $\Lambda_{\mathrm{CB}}^{\mathrm{adj}}$.

The ability of eqs 1 and 2 to mathematically represent the experimental solubility of anthracene in the seven binary alcohol +2 -methoxyethyl ether solvent systems is summarized in Table 2 in the form of "curve-fit" parameters and percent deviations in back-calculated solubilities. Careful examination of Table 2 reveals that both equations provide an accurate mathematical representation for how the solubility of anthracene varies with solvent composition. For the seven anthracene systems studied, the overall average absolute deviation between the experimental and calculated values is $1.1 \%$ and $0.8 \%$ for eqs 1 and 2 , respectively, which is less than the experimental uncertainty. The systems studied cover up to a 27 -fold range in anthracene mole fraction solubility.

From a computational standpoint, eq 1 will likely be preferred because most research groups involved in reporting thermodynamic properties have computer programs for evaluating the Redlich-Kister coefficients. With this idea in mind, we recommend not only that the future presentation of experimental isothermal solubility data for slightly soluble solid solutes dissolved in binary solvent mixtures include a tabulation of the actual observed values but also, if possible, that the solubility data be mathematically represented by eq 1 . Realizing that a single equation will not be applicable to all systems encountered, we further suggest eq 2 as an alternative mathematical representation for systems having extremely large solubility ranges and/ or highly asymmetrical In $x_{A}^{\text {sat }}$ versus $x_{B}^{0}$ curves, such as the carbazole + alkane + tetrahydropyran systems re ported previously (Acree \& al., 1991).

\section{Literature Cited}

Acree, W. E., J r. Mathematical Representation of Thermodynamic Properties. Part 2. Derivation of the Combined N early I deal Binary Solvent (NIBS)/Redlich-Kister Mathematical Representation from a Two-Body and Three-Body Interactional Mixing Model. Thermochim. Acta 1992, 198, 71-79.

Acree, W. E., J r. Polycydlic Aromatic Hydrocarbons in Pureand Binary Solvents; Volume 54 in IUPAC Solubility Data Series; Oxford University Press: Oxford, United Kingdom, 1994.

Acree, W. E., J r. Polycyclic Aromatic Hydrocarbons: Binary Nonaque ous Systems: Part 1 (Solutes A-E); Volume 58 in IUPAC Solubility Data Series; Oxford University Press: Oxford, United Kingdom, 1995a. 
J ournal of Chemical and Enginering Data, Vol. 42, No. 2, 1997397

Acree, W. E., J r. Polycyclic Aromatic Hydrocarbons: Binary Nonaque ous Systems: Part 2 (Solutes F-Z); Volume 59 in IUPAC Solubility Data Series; Oxford University Press: Oxford, United Kingdom, 1995b.

Acree, W. E., J r.; Zvaigzne, A. I. Thermodynamic Properties of Nonelectrolyte Solutions. Part 4. Estimation and Mathematical Representation of Solute Activity Coefficients and Solubilities in Binary Solvents Using the NIBS and Modified Wilson Equations. Thermochim. Acta 1991, 178, 151-167.

Acree, W. E., J r.; McCargar, J. W.; Zvaigzne, A. I.; Teng, I.-L. Mathematical Representation of Thermodynamic Properties. Carbazole Solubilities in Binary Alkane + Dibutyl Ether and Alkane + Tetrahydropyran Solvent Mixtures. Phys. Chem. Liq. 1991, 23, 27-35.

Comer, J . F.; Kopecni, M. M. Prediction of Gas Chromatography Solute Activity Coefficients in Mixed Stationary Phases Based on the
Wilson Equation. Anal. Chem. 1990, 62, 991-994.

Zhang, Z.-Y.; Frenkel, M.; Marsh, K. N.; Wilhoit, R. C. Thermodynamic Properties of Organic Compounds and Their Mixtures: Subvolume A: Enthalpies of Fusion and Transition of Organic Compounds; Springer-Verlag: Berlin, 1996.

Received for review October 11, 1996. Accepted December 12 1996. ${ }^{\otimes}$ J .P. thanks the American Association of University Women (AAUW) for a dissertation fellowship.

\section{J E9603234}

${ }^{\otimes}$ Abstract published in Advance ACS Abstracts, February 1, 1997. 